\title{
THE PRIMARY TREATMENT TRIAL: CHANGES IN THE VISUAL FIELD ANALYSIS BY COMPUTER-ASSISTED PERIMETRY
}

\author{
R. A. HITCHINGS, C. S. MIGDAL, R. WORMALD, D. POINOOSWAMY and F. FITZKE \\ London
}

\begin{abstract}
SUMMARY
Computer-assisted perimetry was performed 6-monthly on patients entered into the Primary Treatment Trial using the 30-2 program. Those patients with a minimum of five visual fields had pointwise linear regression analysis (Progressor) carried out. Two consecutive slopes significant at the 0.05 level were taken as evidence for change, either improvement or worsening. Forty-eight patients in the surgery group, 40 in the medical group and 20 in the laser group were suitable for analysis. A comparison of the eyes showing 'improvement' or 'worsening' in the surgery and medicine groups showed no difference between them. This lack occurred despite a significant difference in intraocular pressure between the two groups. The reasons for this lack of difference are discussed.
\end{abstract}

The Primary Treatment Trial was a prospective study which set out to investigate the effectiveness of managing untreated primary open angle glaucoma patients with either primary medical, surgical or laser therapy. The study followed patients for a minimum of 5 years. The criterion for treatment 'success' was an intraocular pressure (IOP) below $22 \mathrm{mmHg}$ at all times. During the trial it became apparent that surgical treatment was the most 'successful', then medicine and finally laser treatment. ' A comparison of IOPs in the medicine and surgery groups showed that the former had consistently higher mean levels and higher daytime variations. ' For the last 3 years of the trial patients were followed by means of computerassisted perimetry. This paper sets out the results of the computer-assisted visual field analysis over that period.

\section{METHODS}

Criteria for entry, follow-up and successful IOP control have been recorded elsewhere.' For the purpose of this analysis all patients in the three groups have been analysed as a member of that group, even though failure of IOP con-

Correspondence to: R. A. Hitchings, Moorfields Eye Hospital, City Road, London ECIV 2PD, UK. trol at some point in time meant that they had to be given additional treatment.

The visual field examinations were performed on a Humphrey computer-assisted perimeter, using the 30-2 program. The patients attended 6-monthly for the examination. A size 3 target was used unless the severity of the visual field defect necessitated the use of a size 5 target. Linear regression analysis was carried out for each individual retinal point. ${ }^{2}$ Those retinal points showing two consecutive significant (at the 0.05 level) positive or negative regression slopes were considered to have improved or worsened respectively. The outer two rows of points in the upper half, and the outermost row of points in the lower half, were not included in the analysis. Only those eyes with at least five visual fields were included.

The false positive and false negative errors, fixation losses and mean deviation in eyes considered to show deterioration and/or improvement were noted. The results for the medicine and surgery groups are presented. The laser group had the highest number of IOP 'failures', which, together with the highest number of irregularities in visual field follow-up, precluded useful analysis.

\section{RESULTS}

'Progression' refers to two consecutive negative regression slopes, and 'no progression' refers to the absence of two consecutive negative slopes, worsening at the $p<0.05$ level. 'Improvement' refers to two consecutive positive regression slopes significant at the $p<0.05$ level. A summary of the results is given in Tables I and II.

It will be seen that there was no significant difference in the false positive and false negative errors between the two groups, suggesting equal performance skills. The patients in the two groups had a similar number of analysable fields (Table I).

Progression was found after the fourth or fifth field, while improvement was found by the third or fourth field. An eye could improve and then deteriorate; the opposite was not seen. There was no significant difference between the starting mean deviation in the two groups (Table I). 
Table I. Baseline data

\begin{tabular}{|c|c|c|}
\hline & Surgery & Medicine \\
\hline No. of patients & 57 & 56 \\
\hline No. of analysable patients & 48 & 40 \\
\hline \multicolumn{3}{|c|}{ No. of analysable VF per patient } \\
\hline Progression & 7.00 & 6.62 \\
\hline No progression & 7.06 & 6.93 \\
\hline \multicolumn{3}{|l|}{ False positive errors } \\
\hline Progression & $4.74 \%$ & $3.31 \%$ \\
\hline No progression & $3.14 \%$ & $3.71 \%$ \\
\hline \multicolumn{3}{|l|}{ False negative errors } \\
\hline Progression & $15.30 \%$ & $32.06 \%$ \\
\hline No progression & $23.14 \%$ & $22.79 \%$ \\
\hline \multicolumn{3}{|l|}{ Fixation losses } \\
\hline Progression & $11.79 \%$ & $9.46 \%$ \\
\hline No progression & $4.93 \%$ & $8.57 \%$ \\
\hline \multicolumn{3}{|l|}{ Mean deviation ${ }^{\mathrm{a}}$} \\
\hline Progression & $11.53 \quad($ SD 6.44) & $16.40 \quad($ SD 9.48) \\
\hline No progression & $12.00 \quad($ SD 5.85) & (SD 7.05) \\
\hline
\end{tabular}

'Progression' means one or more locations with two or more consecutive negative regression slopes. 'No progression ' means no locations with significant negative regression slopes. False negative, false positive and fixation losses were calculated from the last recorded value for each eye.

${ }^{a}$ Taken from the average of the second and third mean deviations for each eye.

There was no significant difference between visual field change in the two groups despite a significant difference in IOP (Table II).

\section{DISCUSSION}

Computer-assisted perimetry offers the advantages of a mechanically repeatable test performed under optimum conditions with quantifiable results available for statistical analysis. ${ }^{3.4}$ The perimetrist's role is to encourage, cajole and support the patient throughout the test to minimise the effects of boredom and fatigue. The results are obtained from threshold determination of retinal sensitivity usually within the central $30^{\circ}$ and are expressed as global indices, ${ }^{5,6}$ giving an indication of within-test (short-term) fluctuation as well as any overall or localised reduction in retinal sensitivity. The patient's performance is noted as a percentage of fixation, false positive and false negative errors, ${ }^{5,6}$ all of which may increase with time spent on the test $^{7}$ as well as with severity of the visual loss, ${ }^{3}$ age, ${ }^{8}$ refraction $^{9,10}$ and eccentricity, ${ }^{11.12}$ and lens opacities ${ }^{13}$ and miotics.

In glaucomatous eyes the test-retest variability precludes useful analysis of a sequence of two (or even three) fields. ${ }^{4,13,14}$ Performance does improve with practice ${ }^{14-18}$ for in many cases change may reflect only regression to the mean. ${ }^{19.20}$ For the patients reported on here, improve- ment was seen in up to five fields, the minimum number considered for analysis.

The Humphrey perimeter has 'inhouse' software for analysis of visual fields (Statpac, and Statpac 2) and use of such indices has proved of use in recognising glaucomatous change, ${ }^{21}{ }^{24}$ either singly or in clusters. ${ }^{2+}$ The recognition of change in a sequence of fields has proved more elusive. A preliminary study showed disagreement among experienced observers. ${ }^{25}$ Not only have the changes due to short-term and long-term fluctuation to be taken into account, but in the absence of knowledge of the natural history of the condition, allowance has to be made for the anticipated mode of progression of the visual loss. ${ }^{26}$ To date assumptions on visual loss assume a linear character of the loss. Analyses of change have been based either on an analysis of change between the 'latest' field and a baseline field (in practice an average of two or three fields) ${ }^{22.23}$ or on linear regression of either areas in the field ${ }^{27.28}$ or individual retinal locations. ${ }^{2.29}$ The patients in this study have already been subjected to a preliminary linear regression analysis of individual retinal points, ${ }^{29}$ and this study has reported on a final analysis.

Linear regression failed to demonstrate a difference between the two groups despite a significant difference in IOP (and visual loss noted on Friedman fields) occurring between them. Two reasons exist for this: the analysis method, and the timing of the tests.

Table II. Visual field changes and intraocular pressure

\begin{tabular}{lcc}
\hline & Surgery & Medicine \\
\hline Eyes 'worse' at $p<0.05$ & $34(71 \%)$ & $25(63 \%) \mathrm{NS}$ \\
Av. no. of locations & $4.4(\mathrm{SD} 4.0)$ & $5.58(\mathrm{SD} 4.48) \mathrm{NS}$ \\
Eyes 'improved' & $20 / 40(50 \%)$ & $12 / 36(33 \%)$ \\
Av. no. of locations & 2.00 & 2.00 \\
Mean IOP & & 19.03 (SD 1.81) $p<0.001$ \\
$\quad$ Progression & 14.17 (SD 2.69) \\
$\quad$ No progression & 13.19 (SD 3.25) & 19.39 (SD 2.31) $p<0.001$ \\
\hline
\end{tabular}

'Progression' means eyes with one or more location with a negative regression slope. 'No progression' means eyes without locations having a negative regression slope. 
Linear regression analysis has been criticised as a good method of diagnosing cataracts (A. Heijl, personal communication, Singapore 1990). The insertion of a filter in the visual system will cause progressive decline in sensitivity of all retinal locations. It could be expected that the decline would be greatest in the damaged areas of the visual field. Eyes in this series showed localised decline in the visual field at a time when the central acuity was unchanged. Although developing lens opacities could not be excluded from some contribution to this change, the localised nature of the change seems to rule them out as the major cause. Deterioration was considered to have occurred when there were two significant negative regression slopes, i.e. the decline was maintained upon repeating the visual field after an interval of 6 months. This should exclude poor performance on one day of the test.

The method of visual field testing is open to criticism in the light of experience gained over the last 8 years. The patients in our series showed improvements in performance, i.e. increased retinal sensitivity, in up to five visual fields. If deterioration was occurring it was masked by the improved performance. Only when reduced sensitivity exceeded learning could deterioration become manifest. This was seen in fields five to seven. Recent lare-scale glaucoma trials have insisted on pretrial training in perimetric testing to remove the learning effect before entering patients. ${ }^{31.31}$ Our patients learnt 'on the job', minimising the chances of detecting differences between groups.

The computer-assisted perimeter was used only for the last 3 years of the study. It could be that visual loss occurred in eyes the initial (medical) treatment of which had not achieved adequate lowering of IOP. ${ }^{32}$ This raises the possibility that in our series the visual loss had occurred by the time we looked for it with the Humphrey perimeter. However, this possibility seems unlikely as Kaplan-Meier analysis shows the progression occurring in the Friedman field throughout the study. ${ }^{33}$

Is the computer-assisted perimeter too sensitive a test for glaucoma patients? Many patients in this series had severe visual loss. This may have made it more difficult for them to give consistent performances on testing, and in many cases limited them to a size 5 target. A disproportionate number of patients in the laser group were unable to perform adequately, precluding analysis. Patients with central islands of vision would do best on a 10-2 test. For useful follow-up information to be obtained from computer-assisted perimetry a test appropriate to the visual field has to be chosen. No deterioration can be expected to be identified until the patient has 'learnt' to do the test. Finally, if the patient 'has a bad day' with high error scores, then the test result should be ignored and the test repeated.

It would appear that the IOP difference between the medicine and surgery groups could account for the differences in visual field performance. Whether this is due to the mean IOP or spikes of IOP in the medical group detected only on annual phasing is not clear. This finding is in agreement with previously published studies ${ }^{3+-37}$ where the importance of visual loss occurring at the higher normal IOPs has been stressed (up to $73 \%{ }^{37}$ ). However, it is of interest to note that not all studies confirm this. ${ }^{38}$

The results obtained with a computer-assisted perimeter could not identify differences attributable to IOP differences between groups. The Friedman analyser mark I is a simple machine, testing a small part of the visual field. The separation of test locations and the simple test strategy (using three isopters-threshold, $0.4 \log$ units below threshold and 'absolute' defects) make it unlikely that it was a more sensitive test than the Humphrey perimeter. Changes between the groups could be seen on Friedman analysis by 24 months into the study. ${ }^{39}$ It seems likely that using the appropriate test strategy, with the precautions outlined above, computer-assisted perimetry would identify deterioration even sooner.

\section{REFERENCES}

1. Migdal CS, Hitchings RA. Control of chronic simple glaucoma with primary medical, surgical and laser treatment. Trans Opththalmol Soc UK 1986;105:653-8.

2. Noureddin BN, Poinooswamy D, Fitzke F, Hitchings RA. Regression analysis of visual field progression in low tension glaucoma. Br J Ophthalmol 1991;75:493-5.

3. Heijl A. Computerised perimetry. Trans Ophthalmol Soc UK 1985:104:76-81.

4. Heijl A. Computerised perimetry in glaucoma management. Acta Ophthalmol (Copenh) 1989;67:1-12.

5. Flammer J. The concept of visual field indices. Graefes Arch Clin Exp Ophthalmol 1986:224:389-92.

6. Bickler-Bluth M. Trick G. Kokler A. Cooper DG. Assessing the utility of reliability indices for automated visual fields. Ophthalmology 1989;96:616-9.

7. Heijl A. Drance SM. Changes in differential threshold in patients with glaucoma during prolonged perimetry. Br J Ophthalmol 1983:87:512-6.

8. Katz J. Sommer A. A longitudinal study of the age-adjusted variability of automated visual fields. Arch Ophthalmol 1987:105:1083-6.

9. Heuer DK, Anderson DR. Feuer WJ, Gressel MG. The influence of refraction accuracy on automated perimetric threshold measurements. Ophthalmology 1987:94:1550-3.

10. Weinreb RN. Perlman JP. The effect of refractive correction on automated perimetric thresholds. Am J Ophthalmol 1986:101:706-9.

11. Heijl A, et al. Normal variability of static perimetric threshold values across the central visual field. Arch Ophthalmol 1987:105:1544-9.

12. Flammer J. Drance SM. Fankhauser F, Augustry L. Differential light threshold in automated static perimetry: factors affecting short term fluctuation.

13. Lam BL. Alward WLM. Kolder HE. The effect of cataract on automated perimetry. Ophthalmology 1991;98:1066-70.

14. Piltz J. Starita RJ. Test retest variability in glaucomatous visual fields. Am J Ophthalmol 1990;109:109-11.

15. Heijl A, Lindgren, Lindgren G. Test-retest variability in glaucoma. Am J Ophthalmol 1989;108:130-4.

16. Heijl A, Lindgren G, Olsen J. The effect of perimetric experience in normal subjects. Arch Ophthalmol 1989;107:81-6.

17. Werner EB, Adelson A. Krupin T. Effect of patient experience on the results of automated peimetry in clinically stable glaucoma patients. Ophthalmology 1988;95:764-7.

18. Rutishauser C. Flammer J. Retests in static perimetry. Graefes Arch Clin Exp Ophthalmol 1988:226:75-7. 
19. Smith TJ. The effect of regression towards the mean on visual disability rating scales. Doc Ophthalmol 1989;70: $331-7$.

20. Enger C, Sommer A. Recognising glaucomatous field loss with the Humphrey Statpac. Arch Ophthalmol 1987;105:1355-7.

21. Katz J, Sommer A. Screening for glaucomatous visual field loss: the effect of patient reliability. Ophthalmology 1990;97:1032-7.

22. Tsai CS, Shin DH, Wan JW, Zeitter JH. Visual field global indices in patients with reversal of glaucomatous cupping after intraocular pressure reduction. Ophthalmology 1991;98:1412-9.

23. Boeglin RJ, Caprioli J, Zaulauf M. Long term fluctuation of the visual field in glaucoma. Am J Ophthalmol 1992;113:396-400.

24. Chauhan B, Henson DB, Hobley AJ. Cluster analysis in visual field quantification. Doc Ophthalmol 1988:69:25-9.

25. Werner EB, Bishop KI, Koelle J, et al. A comparison of experienced clinical observers and statistical tests in detection of progressive visual field loss in glaucoma using automated perimetry. Arch Ophthalmol 1989;106:619-23.

26. Mikelberg F, Schulzer M, Drance SM, Lau W. The rate of progression of scotomas in glaucoma. Am J Ophthalmol 1986;101:1-6.

27. Wu DC, Schwartz B, Nagin P. Trend analysis of automated visual fields. Doc Ophthalmol Proc Ser 1986;49:175-9.

28. O'Brien C, Schwartz B, Takamoto T, Wu DC. Intraocular pressure and the rate of visual field loss in chronic open angle glaucoma. Am J Ophthalmol 1991;111:491-500.

29. Hitchings RA, Migdal CM, Fitzke F. Intraocular pressure control: does it protect the visual fields? In: Kricglstein G, editor. Glaucoma update IV. Berlin: Springer-Verlag, 1991.
30. Glaucoma Laser Trial Research Group. The Glaucoma Laser Trial (GLT). II. Results of argon laser trabeculoplasty versus topical medicines. Ophthalmology 1990;97: 1403-12.

31. Schulzer M. The Normal Tension Glaucoma Study Group. Intraocular pressure reduction in normal tension glaucoma. Ophthalmology 1992;99:1468-70.

32. Jay JL, Murray SB. Early trabeculectomy vs. conventional management in primary open angle glaucoma. Br J Ophthalmol 1988;72:881-90.

33. Migdal CM. Hitchings RA. Gregory M. Effect of mean IOP levels on visual field preservation in treated glaucoma patients. Paper presented at the Annual Congress of the Royal College of Ophthalmologists, May 1993.

34. Hart WM, Becker B. The onset and cvolution of glaucomatous visual field defects. Ophthalmology 1982;89:268.

35. Mao LK, Stewart WC. Shields MB. Correlation between intraocular pressure control and progressive glaucomatous damage in primary open angle glaucoma. Am J Ophthalmol 1991:111:51-5.

36. Vogel R, Crick RP, Newson RB, Shipley M, Blackmore H, Bulpitt CJ. Association between intraocular pressure control and loss of visual field in chronic simple glaucoma. Br J Ophthalmol 1990:74:3-6.

37. Palmberg P. Epidemiology of POAG and rationale for therapy. Glaucoma Abstr 1969;6:10-23.

38. Chauhan BC, Drance SM. The relationship between intraocular pressure and visual field progression in glaucoma. Graefes Arch Clin Exp Ophthalmol 1992;230:521-6.

39. Migdal CS, Clark P, Hitchings RA. Glaucomatous field changes related to the method and degree of intraocular pressure control. Doc Ophthalmol Proc Ser 1987;49:371-6. 